\title{
Un ojo responsable frente al dolor de los demás: imágenes de la violencia en dos films del Grupo Ukamau
} An responsible eye to the pain of others: images of violence in two films of Ukamau Group Um olho responsável perante a dor dos outros: imagens de violência em dois filmes do Grupo Ukamau

María Gabriela Aimaretti ${ }^{1}$

\footnotetext{
1 Maria Aimaretti es Doctora en Teoría e Historia de las Artes por la Universidad de Buenos Aires. Licenciada y profesora en Artes Combinadas por la Facultad de Filosofía y Letras de la UBA. Becaria doctoral del CONICET (2010-2014), actualmente es becaria post-doctoral por ese mismo organismo de investigación científica. Docente universitaria en la cátedra de Historia del Cine Latinoamericano y Argentino dictada en la carrera de Artes, FFyL UBA. Docente invitada en seminarios de maestría en la Facultad de Filosofía y Letras. Miembro del grupo de investigación CIyNE (2007-2015), e investigadora invitada en UNTREF (2011-2015). Responsable de la sección "Reseñas bibliográficas especializadas" y miembro del comité editorial de la Revista Cine Documental (www. cinedocumental.com.ar) (2010-actualidad).
} 
Resumen: La revelación de las distintas expresiones de la violencia política -institucional, económica, social y simbólica-, y la problematización del ejercicio de la fuerza "desde abajo" en pos de un cambio revolucionario, han sido tópicos recurrentes en la producción de Jorge Sanjinés y el Grupo Ukamau (GU). Este trabajo analiza en dos de sus films, Revolución (1963) y Yawar mallku (1969), el tratamiento de su representación y las modalidades de denuncia e impugnación del orden hegemónico. Ambas producciones ponen en crisis las formas y relatos de la Historia y reponen lo no dicho-no visto de la violencia contra los cuerpos y las identidades culturales de los sectores indígenas y populares.

Palabras clave: Grupo Ukamau; revolución; violencia; política.

Abstract: The revelation of the different expressions of political violence -institutional, economic, social and symbolic-, and the problematization the use of force "from below" towards a revolutionary change, have been recurring topics in production of Jorge Sanjinés the Ukamau Group (GU). This paper analyzes in two of his films, Revolution (1963) and Blood of the Condor (1969), treatment of representation and modalities of reporting and challenge the hegemonic order. Both productions put in crisis forms and stories of History and replenish unsaidnot views of violence against bodies and cultural identities of indigenous and popular sectors.

Key words: Ukamau Group; revolution; violence; politics.

Resumo: A revelação das diferentes expressões de violência política-institucional, econômica, social e simbólica, e a problematização do uso da força "de baixo" depois de uma mudança revolucionária, tem sido temas recorrentes na produção de Jorge Sanjinés e do Grupo Ukamau (GU). Este trabalho analisa em dois de seus filmes, Revolução (1963) e Sangue do Condor (1969), o tratamento de sua 
representação e as modalidades de denúncia e desafio à ordem hegemônica. Ambas produções põem em crise as formas e relatos da História e repõem a violência não-dita - não-vista contra os corpos e as identidades culturais dos setores indígenas e populares.

Palavras-chave: Grupo Ukamau, revolução, violência; política.

\section{De la construcción de una praxis (y una mirada) al servicio de la revolución}

La tarea del Grupo Ukamau (GU) ha sido y es no sólo original, sino cardinal en lo que hace al desarrollo del cine local, regional y al movimiento del "Nuevo Cine Latinoamericano", funcionando como referente ineludible en discusiones, foros y encuentros. Desde principios de la década del sesenta el grupo - inicialmente formado por Jorge Sanjinés, Oscar Soria y Ricardo Rada- desarrolló un proceso de crecimiento integral que incluyó una dimensión técnica, una ideológica y otra cultural. Mientras adquiría experiencia en el manejo de elementos narrativos y tecnológicos del dispositivo fílmico, profundizaba sus lecturas y conocimientos políticos y se introducía en las cosmovisiones y lenguas originarias. Así logró complejizar su mirada sobre el universo socio-cultural del país al que re-descubrió e intentó "defender" del avasallamiento imperialista, produciendo un tipo de análisis marxista con contenidos étnicos: «La primera interpretación de la realidad boliviana identificada con un análisis de las diferencias raciales, deja paso a la presencia de dos elementos primordiales: el enemigo identificado con el imperialismo y la apreciación de lo indígena como parte de un conjunto de clases sociales en pugna» (MESA, 1985, p. 80).

Obra de montaje, sin diálogos ni voz over, Revolución (1963) es el puntapié inicial de un camino de búsqueda estética y política. A lo largo de dos años, entre 1962 y 1963 y en el marco de su "Escuela Fílmica Boliviana”, Sanjinés, Soria y Rada elaboraron este cortometraje documental en $16 \mathrm{~mm}$ sustrayendo material virgen de producciones auspiciadas. El material filmado quedó guardado y luego, mientras Sanjinés revelaba en Buenos Aires un trabajo por encargo comenzó a montarlo. En medio de un clima de fuerte inestabilidad política, el film no pudo ser difundido oficialmente en Bolivia. Según Sanjinés, el presidente Víctor Paz Estenssoro «encontró que los uniformes de los hombres de su guardia se parecían demasiado 
a los de las tropas represivas que se mostraban en la pantalla. No autorizó su salida. Proyectamos Revolución clandestinamente a los obreros y a los mineros» (SANJINÉS, 1979, p. 11). Considerado el primer film independiente después de muchos años de subvención estatal o privada, Revolución puede ser leído como «una reconstrucción poética del 9 de Abril de 1952» (DAGRÓN, 1982, p. 219). ${ }^{2}$ Sin embargo, en tensión con esta interpretación y a raíz de las dudas generadas por la política del Movimiento Nacionalista Revolucionario (aunque sin llegar a romper programáticamente con él), también puede ser visto como el anuncio de una Revolución por venir que acabe con la opresión imperialista que una primera Revolución, inacabada, no pudo cumplir.

A posteriori, el grupo fue autocrítico con esta primera etapa "defensiva" y con Revolución considerando que, si bien ponía en imagen la deplorable situación en la que vivían los sectores populares, no daba a conocer nada nuevo a sus destinatarios privilegiados: esos mismos sectores empobrecidos. Había que explicar la miseria, conocer quienes la ocasionaban, a fin de que de esa comprensión emerja una lucha conciente y lúcida.

En un momento en el que la política se convirtió en una región que dotaba de sentido a prácticas y representaciones (TERÁN, 1991), y en el que poco a poco se naturalizó la violencia como estrategia para la toma del poder, el grupo postula al cine como arma de combate, un medio de reflexión por el cual el pueblo puede rememorar sus experiencias de lucha en función de su emancipación. Así se pasa de la denuncia y la táctica defensiva-descriptiva, a otra ofensiva-explicativa, de desenmascaramiento de la violencia imperialista y combate contra ella: «Este cine que llamaríamos revolucionario, que cada vez se hacía más radical en sus planteamientos, es un cine que no cuenta historias, sino de alguna manera, hace historia, porque influye en el proceso, penetra en el proceso histórico» (SANJINÉS en FRÍAS, 1979, p. 89). Yawar Mallku (1969), que en quechua significa "Sangre de Cóndor" (animal que simboliza al jefe de una comunidad, mallku o jillakata), es la primera película de este período:

En primera instancia la definición política se va clarificando. Términos como opresor-oprimido, país dependiente, imperialismo, burguesía criolla como factor de poder, ejército defensor de los intereses de la élite, etc. son conceptos no sólo manejados con frecuencia, sino que van conformando una plataforma a través de la cual debemos ver a un director que

2 Dijo Sanjinés: "Queríamos hablar de los móviles de la "revolución" inspirándonos en los sucesos revolucionarios de Abril de 1952 que había cambiado tanto la realidad de Bolivia. Ese proceso había sacado a mi país de sus estructuras semi-feudales y lo había puesto en el carril de la democracia burguesa (...) Bueno, todo ese proceso tremendo, complejo, apasionante era nuestro tema y nos pusimos a filmar una historia individual que nos serviría de eje para contar la historia con mayúsculas! Sin embargo, todo era muy difícil, no encontrábamos ningún apoyo (...) así que pudimos llegar a filmar tal vez sólo un diez por ciento de nuestro gran proyecto» (SANJINÉS, 1999, p. 30-31). 
ha optado por mostrarnos la realidad -y no sólo como una referencia- como afirmación de contradicción e injusticia permanentes e institucionalizadas. La violencia como hecho cotidiano mueve a las respuestas violentas que propone Sanjinés (MESA, 1985, p. 86-87).

El GU había conocido el problema de la esterilización inconsulta a través de un periódico de La Paz y la radio "Fides", y aunque fue difícil encontrar pruebas, un grupo de médicos confirmaron haber conocido un caso, y a partir de esta noticia se construyó una historia de ficción. La película comenzó a prepararse en medio de un enrarecido clima político tras la muerte "accidental" del presidente Gral. René Barrientos Ortuño (abril de 1969), y ante un probable giro hacia la derecha del gobierno de turno. ${ }^{3} \mathrm{Si}$ bien las posibilidades económicas reales de concretar el proyecto eran exiguas, la solidaridad hizo posible la reunión del dinero bajo una suerte de "cooperativa". ${ }^{4}$

Inicialmente su estreno en La Paz fue prohibido y la película censurada. Sin embargo el grupo movilizó a la prensa, organizaciones universitarias y público en general, y preparó una protesta que fue reprimida violentamente. ${ }^{5}$ Cuando en agosto de 1969 el film se vió en Venecia y Sanjinés declaró que su película mostraba cómo el gobierno quería extinguir a los grupos indígenas, el semanario boliviano "Hoy" publicó una nota donde se calificaba al director de sicótico político subrayando el daño que provocaba al país. Si bien la película tuvo una buena recepción en las ciudades, el grupo comprendió durante las exhibiciones en el campo que habían reproducido modelos de representación occidental justamente cuando su objetivo era acercarse a los sectores indígenas y problematizar la pregunta ¿cuál es el lugar del indio en su liberación?:

(...) era muy doloroso decir: nosotros hemos hecho una película para movilizar a los campesinos bolivianos y resulta que los campesinos bolivianos ven a esa película como otra nueva intromisión cultural en su cultura, en su medio. No la sentían como propia. Porque no estábamos manejando el lenguaje bien, un lenguaje que fuera coherente con esa cultura y no se trata de rebajar el tono y la didáctica, sino de

\footnotetext{
3 Efectivamente el presidente interino Siles Salinas fue derrocado en septiembre de ese año.

4 Oscar Soria recordó: «Muchos amigos contribuyeron a la financiación (...) la Confederación Médica Boliviana dio los primeros aportes. Y luego otras entidades y amigos nos ayudaron (...) El grupo de médicos, por ejemplo, decidió que todos los aportes fueran asimilados a los gastos sin devolución por parte de los realizadores» (Soria en Frías, 1979, p. 85-86). Incluso algunos desconocidos al grupo, gracias a la información de la prensa, colaboraron con pequeñas sumas de dinero, mientras Soria empeñó su casa y cada miembro de Ukamau puso dinero de sus ahorros personales. En esta película ya es miembro del grupo Antonio Eguino (director de fotografía).
}

5 Gumucio Dagrón (1982, 1982b) cuenta que la prohibición se debía a presiones de la Embajada Norteamericana, vía el Departamento de Espectáculos de la Alcaldía Municipal. Gracias a la presión del público, se hizo posible el estreno en medio de un clima de enorme tensión. 
entender los ritmos internos y otra cosmovisión que tenía y que tiene esa gente (SANJINÉS en DAICICH, 2004, p. 108).

Esta película fue no sólo un enorme paso de aprendizaje autocrítico: se había logrado pasar a un discurso analítico y explicativo en vistas a la toma de conciencia de los sectores subalternos sobre su explotación por el imperialismo norteamericano y sus "aliados" locales y la necesidad de un cambio revolucionario. ${ }^{6}$

\section{En torno a la representación de la violencia: el ojo responsable}

Una de las preocupaciones centrales, tanto en su producción audiovisual como escrita, a la que el GU se ha abocado es la violencia política y la revelación de sus distintas expresiones: Revolución y Yawar mallku son dos claros ejemplos al respecto. La relevancia del tema radica en que en la pregunta por los límites y el uso de la fuerza - para oprimir, o para liberarse - se juega la base sobre la que se piensa el orden de lo posible y lo imposible: es decir, qué cuenta como humano, o en términos de Judith Butler (2006) qué vida es considerada vivible y qué muerte lamentable y, correlativamente, qué queda dentro/fuera del campo de lo visiblelegible, lo públicamente reconocido-legal.

Las prácticas represivas, la exclusión social y la segregación que cuestionan las obras que nos ocupan conducen tanto a la re-visibilización de sujetos sociales subalternizados cuya muerte pareciera ser "no-lamentable", como a la reflexión incisiva en tono a la supuesta "igualdad" de derechos. El sentido de impugnación al orden vigente que portan las películas insiste en el derecho a tener derechos, el derecho a una vida digna donde la felicidad no se escamotee: una vida que siempre cuente como humana. Por eso la condena a la violencia va en paralelo a historiar su ocurrencia y revisar el tipo de mundo que la permite (y la hace visible o no). De este modo los films re-figuran la humanidad humillada, desfigurada, en pos de recobrar el sentido de indignación responsable por el Otro. Responsabilidad supone aquí la composición de una mirada - un ojo- que “soporta”, sostiene, ampara la precariedad de la Vida y la preserva de ser edulcorada en una forma visual que simplifique o estereotipe el sufrimiento acaecido; asumiendo el parpadeo de la representación de la violencia, es decir la imposibilidad de aprehensión o captura completa del dolor humano. Incluso dando a ver esos cuerpos inquietantes, frágiles, hay "algo" inabordable, intraducible, que apenas logra ser intuido.

6 La difusión de este trabajo generó que muchas comunidades indígenas rechazaran la intervención de los Cuerpos de Paz, se crearan comisiones de investigación en el Senado y la Universidad Mayor de San Andrés (La Paz) y que, más adelante, durante el gobierno progresista del Gral. Juan José Torres (19701971), investigaciones oficiales provocaran la salida del país de esos organismos norteamericanos. 
Resituando el ojo sobre los límenes de lo subalterno, los films figuran el dolor a través de la mostración de zonas de inquietud que vuelven «perceptible aquello que queda por fuera de un campo determinado de visión» (STEGMAYER; CUESTA, 2012, p. 7), dan a ver lo que perturba la narración dominante y su memoria hegemónica abriendo un territorio de riesgo. En esos espacios de dolor o zonas de inquietud que el ojo figura a sabiendas de su (im)potencia: «los sujetos que los habitan devienen figuras de malestar (...) pone[n] en cuestión radical la ficción de soberanía del Estado Nación. En esos espacios, el ciudadano es un no-ciudadano, el hombre es un no-hombre (...) Allí el espacio y el cuerpo son "inhabitables"» (BÁRCENA; MÈLICH, 2003, p. 195).

\section{Del pequeño alumbramiento del ojo responsable}

Revolución señala la raíz inaugural respecto no sólo de la producción de Ukamau sino de un nuevo momento para el desarrollo del cine boliviano. La fundación-fundamento de lo que será una fecunda trayectoria, pero hecha en pequeño formato, sin una estructura argumental convencional y "con retazos" de celuloide:

Revolución es el comienzo de una nueva estética que integra
a Bolivia en esa perspectiva latinoamericana del cine, apoyada
en la realidad y en la conciencia aguda de cambio que debe
partir del pueblo. La capacidad mostrada en base a un lenguaje
puramente visual, superando un viejo vicio del documental
boliviano habitualmente sobrematizado por el texto en off,
y la fuerza del movimiento de cambio que hace vislumbrar
ya la antinomia opresor-oprimido, nos permite hablar de
un nuevo cine pensado en la dimensión que ofrece como
lenguaje y que debe ser testimonio y vehículo para la crítica y
problematización del espectador (MESA, 1979, p. 39).

Con un montaje pausado y el acompañamiento en over de Atahualpa Yupanqui ${ }^{7}$, el film se inicia con la descripción de las condiciones de vida de ancianos y niños que viven entre edificios derrumbados y restos de basura. Las acciones registradas documentalmente responden a la sobrevivencia (buscar algo para comer o vestirse, mendigar) y son representativas de un ritmo que se presume cíclico y repetitivo. Los planos generales permiten la contextualización de este drama naturalizado/ invisibilizado, y una buena profundidad de campo y el uso del teleobjetivo logran la captación de rasgos y detalles sin intervenir en la realidad. El relato aproxima el ojo

7 Interpreta "Triste N ${ }^{0}$ " en do menor (Córdoba) de Julián Aguirre, presente en el disco de "Canto y Guitarra” (1960). Podemos suponer que el uso de la música de Yupanqui esté dado a partir de los frecuentes encuentros que Sanjinés mantuvo con montajistas y directores argentinos en los laboratorios Alex (Argentina) - todo un espacio de aprendizaje e intercambios- donde fue procesada Revolución. 
responsable: de un plano general que les toma siendo "expulsados" de los huecos que les sirven de reparo para dormir/vivir (bajo tierra, como madrigueras; o en los vaciados de paredes, como cuevas), el montaje va pasando a detalles en pies, manos y rostros que metonímicamente figurarán su corporalidad. Ese tránsito hace posible, aún en la des-delimitación de sus cuerpos confundidos con restos de basura y escombros, una construcción visual aguda del dolor y la exclusión. La insistente mostración de cuerpos y rostros humillados y miserables no apunta a la configuración de una imagen de "pueblo mártir" sino a la concientización punzante a partir de esas zonas de inquietud, no mostradas por el cine local de la época. El diálogo recurrente entre planos detalle de los pies descalzos y primeros planos de rostros, construye un motivo visual bifronte con el que se subraya tanto el despojo y la exclusión, como la fuerza resistente de esa humanidad: la inquietud que provocan estos planos está no sólo en la visibilización del sufrimiento, sino en la capacidad de sobrevivencia. En ese sentido la muerte infantil funciona como metáfora del futuro de las mayorías populares: es por el estado indignante en que vive el futuro de Bolivia, "interrumpido" mucho antes de comenzar a desarrollarse, que la lucha es necesaria y urgente.

La recreación de la Revolución de 1952 es el pretexto para el desarrollo sintético del concepto "Revolución" en tanto horizonte de lucha, de cambio radical de un orden dolorosamente insoportable, "inhabitable". Frente a la inhumanidad de la indigencia y depauperización antes descritas, la representación del trastocamiento de esa realidad no puede ser sino dinámica a través de un montaje rítmico acompañado del sonido efervescente de tambores.

Este segmento es protagonizado por los trabajadores, y su representación, así como el vínculo con su referente, es rica en puntos de vista, angulaciones y tamaños de plano: los trabajadores no son meramente conducidos por el líder, sino que están organizados y luchan en forma conjunta. El GU parece tener presente que, cuando se filma una multitud, «es preciso, como decía Pudovkin, treparse a un techo para seguir los grandes movimientos, después bajar al primer piso para leer mejor los estandartes de la manifestación y, por último, mezclarse con la gente para seguirla desde adentro» (HUBERMAN, 2014, p. 219). El antagonista colectivo de las masas trabajadoras son las fuerzas militares, representantes del status quo desigual y violento. Los planos detalle de las heridas sufridas y las manos engrilladas, la repetición de primeros planos de rostros entre rejas, señalan el hostigamiento sufrido en y tras la represión. Es interesante que, a nivel formal, el relato resuelva la representación de los militares mediante la objetivación de sus cuerpos: han dejado de ser hombres para ser máquinas del terror, armas anónimas sin rostro ni identidad. Los sectores populares, por el contrario, son figurados mediante expresivos primeros planos y la 
detención en la imagen de sus pies prestos para la lucha (en un "soviético" plano detalle que muestra una diagonal de zapatos y refiere a las "filas" de trabajadores organizados) y también yertos en tierra. Los planos de estas figuraciones son más largos, reforzando su pregnancia iconográfica con un sentido didáctico e insistiendo en la denuncia de la violencia y muerte "lamentable" de los sectores populares: así se imponen en el campo de lo visible esas zonas de inquietud-espacios inhabitables.

La última secuencia describe las formas en que la muerte de los luchadores es "elaborada": desde la resignación, el llanto privado de mujeres y niños y la oración religiosa; hasta la indignación pública representada en una caravana que oficia simultáneamente de cortejo fúnebre y marcha de protesta. Pero es la transformación del dolor personal en furor colectivo o la revuelta revolucionaria, aquello que el film preconiza. Tras un corte sonoro dado por la alarma fabril en off, al mostrar de manera alternada rostros y pies, el relato da cuenta de la contraofensiva popular que "se pone de pie" y marcha, hiriendo al enemigo y quitándole sus fusiles: a la violencia reaccionaria se le contrapone la violencia revolucionaria. La tensión ética de la lucha por un orden más justo a través de la violencia está motivada por el peso de la figura de los niños que, en tanto futuro ya vulnerado pero aún resistente, suscita ese "forzamiento" del sistema para generar condiciones de diálogo diferentes (CALVEIRO, 2012). Aunque, como bien lo deja traslucir el film, sean sus primeras víctimas. Por eso es más que significativo el encadenamiento final de primeros planos de niños mientras en banda sonora se oye la balacera de las metrallas y bombas. En el último rostro, y por única vez en toda la película, se realiza un movimiento de cámara interno al plano pudiendo percibirse un cuerpo entero de la cabeza a los pies. En esa figuración-aparición corporal subyace un gesto de reclamo y protesta por la humanidad menoscabada de los sectores más pobres y los trabajadores. Desde la inyección de lo inquietante en la narrativa hegemónica de "lo visible" - un presente inhabitable que "tiene todo que ver" con un pasado revolucionario interrumpido-, la película hace un aporte responsable a la revigorización simbólica y material de una humanidad menoscabada. La reedición y renovación de las luchas emancipatorias, la hondura y el sacrificio de la Revolución por venir, insiste en la tarea inconclusa de terminar con la exclusión y recuperar la dignidad de la Vida de todos, sacando la fuerza, justamente, del dolor que viene de los muertos. 


\section{Un ojo responsable por la sangre derramada}

Yawar Mallku aborda un problema clave para el horizonte revolucionario: la alienación cultural, sea ésta provocada por el Estado a través de dispositivos, instituciones y tecnologías, como desde los propios sujetos subalternos. La esterilización es la figura elegida - a medio camino entre la metáfora y el documentopara representar estas dos formas de alienación: es al mismo tiempo material/vital y cultural; es ocasionada por la acción destructiva de un factor externo (Cuerpos de Paz, Estado, Ciencia Médica) y la autonegación indígena. El film explica el funcionamiento asimétrico del ejercicio del poder desmenuzando las relaciones entre las culturas indígena, criollo-mestiza y norteamericana y, si bien insiste algo dicotómicamente- en cómo los sectores populares buscan la Vida mientras el imperialismo arrastra hacia la muerte y el despojo de la dignidad humana, también muestra el paralelismo de mentalidades y razas que cohabitan el territorio boliviano y el conflicto identitario concomitante, la problemática definición de "lo nacional". La metáfora de la sangre - presente en el título mismo - aglutina los sentidos de vitalidad, herencia, nacimiento e identidad; y también - en su derramamientomuerte, violencia y guerra:

Sin salir del espacio semántico de la fertilidad o infertilidad violentada, Sanjinés va más allá (...) denuncia el doble atentado a las comunidades indígenas: en contra de las mujeres a las que esterilizan y en contra de los hombres que intentan defenderlas de esa violencia. Imperialismo y estado nacional muestran compartir una misma actitud de agresión frente al indio (GARCÍA PABÓN, 1999, p. 98).

Es la violencia ejercida contra Ignacio - figura de malestar ejemplar - lo que la película trata de visibilizar de principio a fin: violencia contra su fecundidad (su mujer, Paulina, ha quedado infértil), ${ }^{8}$ contra su cultura (ninguneo e invisibilización) y contra su cuerpo mismo, siendo el único sobreviviente de un fusilamiento que pretende escarmentar la insolencia indígena con total impunidad hacia la Ley. Su representación expone al espectador al contacto inquietante con el abuso y el despotismo, configurando precisamente un ojo que aprende a ver y estar frente al dolor de aquellas figuras ausentadas del relato hegemónico.

Con audacia, el film se adentra en la crudeza de los bordes liminales de la urbe paceña y la sociedad boliviana desde la perspectiva del indio y el migrante.

8 El film se inicia en la casa familiar de la pareja protagónica donde el mallku Ignacio se lamenta por la muerte de sus hijos y la infertilidad de su mujer a la que reprende verbalmente y golpea. Aunque podría reprocharse el poco espacio que se brinda al tratamiento de la agresión contra las mujeres, resulta audaz dejar planteada la problemática, en una actitud crítica hacia el machismo de la sociedad boliviana. 
Trasladando a Ignacio a La Paz - gravemente herido-, la llegada de Paulina a la ciudad ejemplifica - tal vez algo esquemáticamente- el choque entre la cultura campesina tradicional y la occidental. La música experimental en off comenta el estado interno de confusión y agobio que vive la mujer en ese espacio extraño, hostil, demasiado vertical en oposición a la horizontalidad altiplánica. Pero el personaje que encarna íntegramente la figura del migrante es Sixto, el hermano del mallku, un obrero que reniega de su condición india y se encuentra explotado, convertido en parte de una máquina textil.9 Para dar cuenta de su "violencia interna" basta mostrar su espacio íntimo. La cama en la que se hace descansar el cuerpo sangrante de Ignacio está rodeada de imágenes que simbolizan un conjunto de aspiraciones simbólicas y materiales diametralmente opuestas a la idiosincrasia del mallku (Sixto ha pegado en las paredes, distintos recortes de revista que muestran publicidades y cuerpos femeninos occidentales). Este encuadre visual "de belleza y goce" contrasta patéticamente con el débil y agonizante Ignacio y es el preámbulo del ingreso al hospital: allí su cuerpo doliente, como zona de inquietud, terminará de morir, homogeneizado en un colectivo anónimo de otros cuerpos que no merecen ser vistos ni lamentados.

$\mathrm{Al}$ solicitar Sixto la verdad sobre las razones que llevaron a los gendarmes a disparar sobre su hermano, se desencadena el primer flashback por el que Paulina irá narrado los últimos tiempos de la familia y lo sucedido en Kaata subrayando que, en los rituales de lectura de la hoja de coca y en reuniones comunales, se sospechaba de la acción de los Cuerpos de Paz. Dentro del mismo flashback, y a fin de caracterizar el tipo de vínculo propuesto por los extranjeros se muestra el encuentro que Paulina tuviera con los médicos y que, tal como sostiene Ximena Vergara, simboliza la intervención inconsulta: «En esta transacción, el objeto de comercio es decidor, son huevos, óvulos en potencia, animales impedidos en su desarrollo que devienen comida. Por ende, la gringa, del mismo modo como se queda con los huevos, se ha quedado con los óvulos de Paulina, al dejarlos infecundos» (VERGARA, 2012, p. 184).

Para conseguir el dinero que permita comprar la sangre que necesita su hermano para vivir, Sixto apela a las redes de solidaridad y cooperación que pudo establecer en la ciudad condensadas en la figura de su comadre. Más allá de evidenciar la ineficacia de esta primera fuente de ayuda la escena resulta significativa por aquello que apenas se oye en fuera de campo: una transmisión radial en la que se comenta la interrupción de una huelga obrera, la promesa - limitada- de mejores condiciones

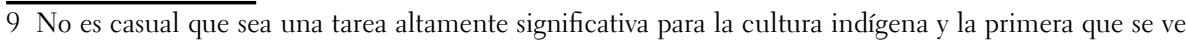
hacer a Paulina al comenzar el film (hilar-tejer), aquella que artificialmente realice Sixto en la fábrica. 
de vida para los trabajadores por parte del presidente, y el anuncio de beneficios para las milicias locales, que reforzarían el desarme de cualquier organización política. Ello señala que el creciente control civil por parte de las Fuerzas Armadas también se desarrolla en la ciudad. Sixto recorrerá La Paz sin hallar comprador alguno para su única pertenencia vendible (la cama), mientras a su alrededor la vida urbana lo ignora por completo. Además de insistir en la frustración por no conseguir dinero, aquí reaparece la presencia ubicua de la fuerza: se trata de una serie de planos que reponen el recorrido de una banda militar por las calles acrecentando la idea de vigilancia previamente señalada, esta vez en clave de estetización de la política.

Entretanto Paulina recuerda otra de las máscaras de la fuerza: los Cuerpos de Paz autopresentándose solidarios y generosos, frente a una silenciosa comunidad fiscalizada de cerca por el alcalde - mediador y traductor entre ambos grupos. En la frase de uno de los médicos extranjeros - "Hemos venido con mucho sacrificio para que ustedes se desarrollen" - resuena el discurso asistencialista de "ayuda" norteamericana tan machaconamente repetido por esos años en Bolivia y que la película se encarga de desmontar dando cuenta de los costos concretos, vitales, de ese "desarrollo". Si los niños reciben las donaciones y se travisten con la ropa de otra cultura, con un resultado algo grotesco; la comunidad realiza luego rituales de ofrenda a los dioses como ruego para "no desaparecer": desbaratando el paternalismo y clientelismo expuesto, la devolución de las prendas es seña de re-aparición y autopresentación de la propia figura (cuerpo político). Por contraste, en el presente del relato Paulina es testigo de la auto-negación de sus hermanos de raza: a pesar de que la enfermera del hospital pregunta a la sala colectiva quién sabe hablar quechua - a fin de transmitirle información a la mujer que no entiende castellano - sólo responde un niño. Los primeros planos de rostros indígenas evidencian las afiatadas prácticas de negación de la propia lengua e identidad que los hace auto-enmudecer y desaparecer.

Habiendo intentando robar dinero en una feria y fracasar, ${ }^{10}$ Sixto recibe un último aviso para salvar a su hermano y se le recomienda ir en busca de un importante médico; mientras en un nuevo flashback se recuerda "ese otro viaje", revelador por cierto, hacia la clínica extranjera que hiciera Ignacio. Ambos hermanos, en tiempos distintos, dispuestos en consonancia y resonancia por el montaje, emprenden viajes: uno en busca de ayuda para salvar una vida, el otro para descubrir la verdad sobre aquel misterioso y fantasmático espacio que la quita. Pero las esperanzas puestas en el ponderado médico, pronto se desvanecen: la indiferencia, desconsideración

10 Es una amarga ironía el que la mujer a la que Sixto intenta robar compre una miniatura de "ekeko" siendo éste el símbolo de la abundancia, la fecundidad y la alegría, ausentes por completo en las historias representadas. 
y ligereza con que se trata el problema de Sixto va desde los hijos del Dr. Reyes que observan pasmados su semblante indígena mientras hablan en inglés entre ellos, hasta el propio médico y su mujer, que celebran un banquete en honor de un grupo de colegas extranjeros. En efecto, los reiterados fracasos de Sixto para reunir dinero, sus pésimas condiciones de vida y creciente desaliento; la falta de respeto a la vida de los y las comunarios/as, la acumulación de derrotas y "falsos ajusticiamientos" históricos sufridos por los sectores populares, potencian la rebeldía contra el orden establecido:

Yawar Mallku posee (...) una cadencia morosa, un aletargamiento temporal que construye tensión pero de modo dialéctico, a través de situaciones/imágenes en contradicción; un in crescendo tensional de rabia, irritación, que atraviesa tanto al protagonista como al espectador; una suma de injusticias, de circunstancias desiguales, atravesadas por el racismo y la soberbia tanto de los científicos norteamericanos, como de quienes lo apañan y actúan en connivencia, que van prefigurando un grado tal de violencia que sólo resta que estalle. La morosidad del ritmo narrativo elegido contribuye así a que ese engendramiento de violencia acceda a una capa de irreversibilidad, a una instancia, que por su lenta y profunda asimilación, al surgir, no habría modo de revertirla (...) (RUSSO, 2010, p. 129).

El relato vuelve entonces al pasado mediante el último flashback para dar cuenta de "otro" tipo de banquete, esta vez de ofrenda a la Pachamama para alejar la muerte de la comunidad que, tras la lectura de la hoja de coca y lo que hubiera visto Ignacio en la clínica, ratifica las sospechas contra "los gringos" a quienes, acto seguido, se ajusticia. Con un uso intensivo y expresivo de los primeros planos y planos medios de los comunarios, en un potente agón discursivo y con un marco sonoro que refuerza el contraste entre la lógica americana (música extranjera) y la local (parlamentos en quechua), la comunidad grita: “(...) Ustedes están matando la vida en el vientre de nuestras mujeres. Ahora vamos a hacer lo mismo con ustedes". Tras lo cual un zoom out muestra el rostro desencajado de uno de los médicos que contesta en fade out: “iMi labor es científica! ¡Mi embajada va a vengarse!”. En efecto, la venganza se opera mediante el alcalde y los gendarmes en el operativo que hemos descrito en el principio de este análisis. En relación al llamado a la violencia "desde abajo" y al contestar sobre la invención del episodio final de castración a los miembros del Cuerpo de Paz dijo Sanjinés en 1971:

En verdad los indios persiguieron a unos miembros del Cuerpo de Paz que estaban alojados en una casa. Los indios los rodearon y los hubieran matado si el alcalde no hubiera 
intervenido (...) Yo creo que, si estamos comunicándonos con la gente de alguna manera, es importante decirles que ellos tienen la capacidad de liberarse. Para mí, esto implica, sencillamente, una llamada a la violencia, una violencia que la gente no ha provocado, pero a la que hasta ahora han sido sometidos. La última toma estática de los brazos levantados en armas significa claramente, y sin duda, que la única solución para que los indios mejoren su situación y para que Latinoamérica se libere es la revolución (SANJINÉS, 1979b, p. 151).

En el presente del relato, el banquete a los "expertos salubristas extranjeros" que vienen a cumplir “altas labores de asistencia”, resulta de un cinismo irritante: el Dr. Reyes subraya la "ayuda y cooperación constructiva que planea nuestro desarrollo y contribuye a él [pues] no hemos sabido seguir el paso acelerado del progreso". $\mathrm{Al}$ no ser atendido, Sixto irrumpe en el salón pero es desestimado por el médico y excluido por completo. A la invisibilización material se suma el lapidario comentario del anfitrión quien aconseja: "Es necesario desterrar al hechicero emplumado y reemplazarlo por el científico. Marchando por el ancho y esplendoroso camino del progreso”. Al volver al hospital, Sixto encontrará a su hermano sin vida.

Tanto la configuración temporal (alternancia de flashbacks con escenas del presente del relato) como el sistema de personajes del film, se organiza a partir de dos centros que se re-envían mutuamente en una dinámica elíptica. En el polo del pasado reciente - cada flashback -, los comunarios e Ignacio han sido agentes políticos activos, y luego castigados y asesinados quedando interrumpida su potencia y autonomía. En el polo del presente, el mallku sufre la inmovilidad como consecuencia de la violencia ejercida, mientras su hermano se activa para salvarle la vida. Sin embargo fracasa cada vez que lo intenta porque a diferencia de Paulina, no retorna al "ayer" (no hace memoria) para comprender mejor cómo actuar en el "hoy"; ni tampoco observa el contexto en el que se inscribe "su problema individual" para encontrar vínculos de semejanza con otros como hiciera Ignacio. Sixto apela a soluciones coyunturales, queda encerrado en las alternativas que el mismo sistema que lo explota y oprime a su hermano "le ofrece" (comprar sangre, fetichización de la vida, del cuerpo). Esta dinámica se quiebra tras la muerte del mallku: es el momento en que, sin renunciar a su condición de obrero, Sixto reasume su identidad étnicocultural y emprende viaje para reunirse con su comunidad e iniciar un camino de lucha (armada). Ello:

(...) no significa, por el hecho de volver llevando nuevamente los atuendos campesinos, una exaltación de lo indio por lo indio. No (...) Sixto toma conciencia y regresa al campo a 
tomar el lugar dejado por Ignacio para continuar la lucha desde el fondo de la nacionalidad, desde el origen de su identidad (...) como un arma más de resistencia respecto del enemigo que intenta disolverla. Su regreso es también un símbolo de la unidad de obreros y campesinos. La lucha de clases está planteada (SANJINÉS, 1980, p. 97-98). ${ }^{11}$

\section{Memoria y redención}

Las películas analizadas parecen alertar: en la memoria del pasado se cifra la potencia del presente y el porvenir, que no son otra cosa que la Revolución, la interrupción de esa "evolución/progreso/desarrollo" que lleva en realidad a la catástrofe, a la muerte, porque es la derrota sin fin de los proyectos emancipatorios. La ampliación de la conciencia histórica, el desenterramiento de las luchas y los mártires populares del pasado y la dignificación del fondo cultural indígena, estimula la acción en el presente hacia un orden que reponga las utopías del pasado incumplidas. Es un tipo de memoria que, leída desde el enfoque de Walter Benjamín (1994), busca redimir el pasado. Uno de sus elementos fundamentales es su carácter crítico respecto del discurso "exitoso" del pasado revolucionario de 1952. Despojada de veneración, la memoria del GU polemiza con una actitud complaciente que obstruiría prácticas de cambio para el aquí y ahora: el develamiento clave es que el pasado revolucionario fue interrumpido y es necesario recuperar la lucha. Por ello la rememoración del ' 52 adquiere un tono crítico - cuando no amargo-, y se propone amplificar y renovar la pasión por la lucha actual.

Revolución enaltece la épica revolucionaria popular, frente a un Estado hipócrita que encarna una "revolución congelada" y un régimen macabro que es imperioso destruir. Incita al cambio revolucionario en tanto horizonte utópico hacia donde la Vida sea Vida para todos, sin exclusión ni represión, admitiendo el uso de la violencia como medio histórico para alcanzar un cambio real. En el caso de Yawar mallku, son los repetidos fracasos individuales y la conciencia creciente de la sangre derramada en el pasado, con el correspondiente confinamiento de lo humano a los espacios de dolor, la rotulación de los sujetos como "figuras de malestar" del relato dominante, etc.; aquello que hace volver a Sixto a su pueblo para emprender la reivindicación de la Vida y la dignidad. Ese movimiento de retorno y concientización responsable es el que se espera del espectador que, sensible/sensibilizado por las zonas de inquietud expuestas en el film, re-politice sus prácticas sociales en pos de un ideal revolucionario.

11 La cita expresa el anhelo que en 1969 se planteaba el GU y parte de la izquierda local: la unión obrerocampesina como forma de impugnación y oposición al pacto militar-campesino instalado por Barrientos. 


\section{Referencias Bibliográficas}

AIMARETTI, M. Producción estética, intervención social y simbolización de la memoria cultural en Bolivia: Grupo Ukamau y Teatro de los Andes. Experiencias de una tendencia de producción cultural de horizonte político. Tesis (doctoral inédita). Universidad de Buenos Aires, Facultad de Filosofía y Letras, Buenos Aires, 2014.

BÁRCENA, F.; MELICH, J-C. "La mirada excéntrica. Una educación desde la mirada de la víctima". En: MARDONES, J.; MATE, R. (eds.) La ética ante las víctimas. Madrid: Anthropos, 2003, p. 195-218.

BENJAMÍN, W. “Tesis sobre el concepto de la historia”. En: Discursos interrumpidos I. Madrid: Taurus, 1994, p. 175-199.

BUTLER, J. Vida precaria. El poder del duelo y la violencia. Buenos Aires: Paidós, 2006.

CALVEIRO, P. "La memoria en tanto espacio ético y político". En: Topografías conflictivas: memorias, espacios y ciudad en disputa. Buenos Aires: Nueva Trilce, 2012, p. 21-30.

DAICICH, O. Apuntes sobre el nuevo cine latinoamericano. La Habana: EICT S.A., 2004, p. 95-115.

FRÍAS, I. L. “Jorge Sanjinés”. En: Los años de la conmoción. México: 1979, p. 79-92. GARCÍA PABÓN, L. “A propósito de la Nación Clandestina”. En: El cine de Jorge Sanjinés. Santa Cruz: Primer Festival de Cine Iberoamericano de Santa Cruz de la Sierra, 1999, p. 90-107.

GUMUCIO DAGRON, A. Historia del cine boliviano. La Paz: Los amigos del libro, 1982.

. Cine, censura y exilio en América Latina. México: STUNAM, CIMCA y Federación Editorial Mexicana, 1982b.

HUBERMAN, D. Pueblos expuestos, pueblos figurantes. Buenos Aires: Manantial, 2014.

MESA, C. "Intento de aproximación al cine boliviano”. En: MESA, Carlos (coord.) Cine boliviano, del realizador al crítico. La Paz: Gisbert, 1979, p.13-65.

. La aventura del cine boliviano. La Paz: Gisbert, 1985.

SANJINÉS, J. "Caminos del Grupo Ukamau”. Revista Octubre N ${ }^{o} 5$ - Enero, México, 1979, p. 10-20.

. "Ukamau y Yawar Mallku”. Entrevista a Jorge Sanjinés. Revista

Afterimage, Londres, n 3, Verano, 1971. En: MESA, C. (coord.) Cine Boliviano: del realizador al crítico. La Paz: Editorial Gisbert, 1979b, p. 135-153. 
. "Nuestro propósito: hacer un cine útil para el pueblo". Conferencia con motivo de la presentación de "Yawar Mallku". Ecuador, 1976, reproducida en Teoría y práctica de un cine junto al pueblo. México: Siglo XXI, 1980, p. 91-99. . "Sobre el cortometraje". En: El cine de Jorge Sanjinés. Santa Cruz: FEDAM y Festival Iberoamericano de Cine de Santa Cruz, 1999, p. 28-33. RUSSO, S. "Yawar Mallku”. En: AA.VV. Cuadernos de Cine Latinoamericano. Jorge Sanjinés y el Grupo Ukamau. Reflexiones y testimonios. Buenos Aires: Tierra del Sur, 2010, p. 127-130.

STEGMAYER, M.; CUESTA, M (2012). "Descentramientos contemporáneos de la memoria. Algunos interrogantes”. Ponencia en Actas Digitales del V SEMINARIO INTERNACIONAL POLÍTICAS DE LA MEMORIA “Arte y Memoria. Miradas sobre el pasado reciente" organizado por Secretaría de Derechos Humanos, Ministerio de Justicia y Derechos Humanos de la Presidencia de la Nación Argentina, Archivo Nacional de la Memoria y Centro Cultural de la Memoria Haroldo Conti, 4, 5 y 6 de octubre de 2012.

TERÁN, O. Nuestros años sesentas. Buenos Aires: Puntosur, 1991.

VERGARA, X. "Fertilizar la memoria, reconstruir la masacre: teorías y prácticas en el cine de Jorge Sanjinés”. En: BONGERS, W. (ed.) Prismas del cine latinoamericano. Chile: Cuarto Propio, 2012, p. 167-190.

\section{Filmografía}

REVOLUCIÓN (Revolução, 1963), de Jorge Sanjinés

Guión: Jorge Sanjinés y Oscar Soria

Producción: Kollasuyo Films- Ricardo Rada

Montaje: Jorge Sanjinés

Fotografía: Jorge Sanjinés

Año: 1963

B y N $16 \mathrm{Mm}$.

Sinopsis: la pobreza y vulnerabilidad de los sectores marginales urbanos se entreteje con la fuerza de las luchas populares por su liberación.

YAWAR MALLKU (Sangre de cóndor, Sangue do Condor, 1969), de Jorge Sanjinés Guión: Jorge Sanjinés y Oscar Soria

Producción: Grupo Ukamau- Ricardo Rada

Montaje: Jorge Sanjinés 
Fotografía: Antonio Eguino

Iluminación: Humberto Vera

Asistente de cámara: Antonio Pacello

Asistente de dirección: Consuelo Saavedra

Asistente de producción: Gladis de Rada

Continuidad: Danielle Caillet

Asesor quechua: René Córdova

Música: Alberto Villalpando, Alfredo Domínguez, Ignacio Quispe, Gilbert Fabre.

Reparto: Benedicta Mendoza Huanca, Marcelino Yanahuaya, Vicente Verneros, Danielle Caillet, Mario Arrieta, Ilde Artés, Comunarios de Kaata

Idioma: quechua y castellano

Año: 1969

B y N 35 Mm.

Sinopsis: es la denuncia fílmica de una campaña clandestina de estilización inconsulta a mujeres indígenas a partir de la historia del líder de una comunidad, Ignacio, y Sixto su hermano. El primero al descubrir que las mujeres de la zona (su esposa incluida) han sido esterilizadas en manos de los Cuerpos de Paz norteamericanos, decide junto a su comunidad vengarse; pero es gravemente herido. Su mujer y su hermano buscarán en la ciudad ayuda para salvar su vida sin conseguirlo. Sixto decide retornar a su comunidad y unirse a la lucha.

submetido em: 11092015 | aprovado em: 06102015 